\title{
A AÇÃO DA COMUNICAÇÃO SOCIAL DO CORPO DE BOMBEIRO MILITAR DE PERNAMBUCO COMO FATOR DE REDUÇÃO DE CRIMES VIOLENTOS LETAIS INTENCIONAIS
}

Klebson Azevedo da Silva ${ }^{1}$

\section{RESUMO}

Os Crimes Violentos Letais Intencionais (CVLI) compreendem todo crime violento que tenha como consequência a morte. Combater esse tipo de crime tem sido um desafio para todos os Estados do Brasil, sobretudo para Pernambuco que chegou a apresentar em 2004 e 2005 a maior taxa de CVLI do País. Os fatores que levam ao cometimento do crime podem estar relacionados tanto com vulnerabilidades sociais como com experiências individuais do cometedor do crime. Pernambuco tem desenvolvido ações que visam a redução do CVLI a exemplo do Programa Governo Presente de Ações Integradas para Cidadania, que entre suas ações está a de oferecer cursos profissionais para pessoas em vulnerabilidade social e do Programa Pacto Pela Vida, reconhecido nacionalmente e internacionalmente pelo seu êxito como política pública de segurança. A cada dia se somam mais atores no combate à violência e a Divisão de Ações Preventivas do Centro de Comunicação Social do Corpo de Bombeiros Militar de Pernambuco, surge então como um novo ator nesse enfrentamento. Suas ações preventivas e educativas, que hoje são realizadas com crianças, podem se expandir e atingir crianças, adolescentes e jovens de áreas socialmente vulneráveis com atividades que promovem a cidadania, o pertencimento de grupo, a responsabilidade social e que são capazes de qualificar os jovens para o mercado de trabalho e gerar dignidade e respeito. Essas ações podem se inserir nos programas já existentes e servirem como fator de redução dos CVLI salvando vidas e construindo uma sociedade mais segura.

Palavras-chave: política Social, ação educacional, prevenção, crimes violentos letais intencionais, vulnerabilidade social.

\footnotetext{
${ }^{1}$ Capitão do Corpo de Bombeiros Militar de Pernambuco, Pós-Graduado em Comunicação Pública e em Comunicação e Oratória. E-mail: klebsoncbmpe@gmail.com
} 


\title{
THE ACTION OF FIREFIGHTERS SOCIAL COMUNICATION AS A FACTOR OF REDUCTION OF INTENTIONAL LETHAL VIOLENT CRIMES (CVLI) IN PERNAMBUCO
}

\begin{abstract}
The Intentional Lethal Violent Crimes (CVLI) is a category for all crime which has as its consequence the death. Fighting against this type of crime has been a challenge for all the federative units of Brazil, especially for the state of Pernambuco, which presented, during the years of 2004 and 2005, the highest level of CVLI in the whole country. The factors that lead to the commitment of CVLI can be related to circumstances such as social vulnerability or individual experiences. The state of Pernambuco has been developing actions that intend to reduce the CVLI's level, for example, the program Governo Presente de Ações Integradas para Cidadania, with actions like offering professional courses to people who are in a condition of social vulnerability, and also the program Pacto pela Vida, known nationally and internationally by its success as a public security program. Day by day, there are more actors in the fight against violence and the Preventive Actions Division of the Center of Social Communication from the Pernambuco's Military Firefighters can be also considered an actor in this fight. Its educational and preventive actions that today are carried out with children, can be expanded and help children and teenagers from socially vulnerable areas. Those activities promotes the sense of citizenship, the feeling of belonging to a social group, the social responsibility, and as its consequences, it can qualify the young people to the job market and generates more dignity and respect. All those actions can be inserted in those programs and make a contribution as a factor of CVLI's reduction, saving lives and building a more secure society.
\end{abstract}

Keywords: Social politics; Educational action; Prevention; Intentional lethal violent crime; Social vulnerability. 


\section{INTRODUÇÃO}

O combate ao CVLI - Crime Violento Letal Intencional é uma realidade em todo o Brasil. As secretarias de segurança pública ou de defesa social em todo o país se mobilizam, juntamente às secretarias de desenvolvimento social, para desenvolverem ações que reduzam de fato o cometimento desse tipo de crime e favoreçam a inserção social e cidadania para indivíduos em vulnerabilidade social. Diante disso confronta-se uma das questões que desafiam as políticas de desenvolvimento social na América Latina: a juventude. Esta, quando em situação de vulnerabilidade social, corre risco de perder perspectivas de futuro, não possuindo condições mínimas que garantam sua participação ativa no processo de conquista da cidadania e acaba por se envolver em ações de pequenos delitos e crimes, perpetuando assim a violência (ALVES; GONTIJO; ALVES, 2013, p.325).

A criança, o adolescente e o jovem cuja trajetória de vida está marcada pela vivência das situações de vulnerabilidade social têm influenciadas as oportunidades que terão e isso pode facilitar o seu envolvimento com práticas criminosas, uso de drogas e álcool. Sendo assim, eles precisam se envolver em ocupações que sejam significativas para a construção de um futuro e que que os distanciem de vícios e práticas delituosas e ao mesmo tempo sejam instrutivas para estabelecimento de valores sociais e morais gerando perspectiva de vida e possibilitando sonhos. (ALVES; GONTIJO; ALVES, 2013, p.328).

Este trabalho tem como objetivo definir como o Corpo de Bombeiros Militar de Pernambuco pode atuar somando esforços na busca de promover segurança e cidadania através de ações desenvolvidas por uma Diretoria de Comunicação Social em programas estaduais de enfrentamento ao CVLI. O trabalho habitual da Comunicação Social da corporação, diretamente 
relacionado com crianças, adolescentes e jovens, desenvolvendo a educação preventiva nas escolas públicas, pode ter um papel ainda mais relevante para suas vidas quando essa atuação apresenta uma possibilidade de qualificação profissional para jovens e a utilização do tempo com qualidade para crianças e adolescentes.

\section{OBJETIVOS}

- Definir Crime Violento Letal Intencional e possíveis fatores sociais que potencializam a sua ocorrência.

- Identificar ações de comunicação social que podem ser inseridas no trabalho com crianças, adolescentes e jovens em situação de vulnerabilidade.

- Definir uma ação social do Corpo de Bombeiros Militar de Pernambuco, através do Centro de Comunicação Social - CCS, visando favorecer a redução dos CVLI.

\section{MÉTODO}

Trata-se de um projeto de intervenção introduzido por uma revisão bibliográfica narrativa, ou seja, uma pesquisa baseada na análise da literatura já publicada em forma de livros, revistas, publicações avulsas, imprensa escrita eletronicamente, disponibilizada na Internet ou meio físico.

A abordagem foi qualitativa, segundo Goldenberg, (1997, p.34) que afirma que "a pesquisa qualitativa não se preocupa com representatividade numérica, mas, sim, com o aprofundamento da compreensão de um grupo social, de uma organização, etc.".

Os procedimentos seguiram a definição de Minayo (2001, p.14), para pesquisa bibliográfica: "os exemplos mais característicos desse tipo de 
pesquisa são sobre investigações sobre ideologias ou aquelas que se propõem à análise das diversas posições acerca de um problema".

Após a análise do material pesquisado foi estruturado um projeto de intervenção para atuação do Corpo de Bombeiros Militar de Pernambuco no combate ao Crime Violento Letal Intencional, através da Diretoria de Comunicação Social da instituição.

A pergunta norteadora utilizada para direcionar o estudo em questão foi: Como o Corpo de Bombeiros Militar de Pernambuco pode atuar de forma efetiva contra o CVLI através da ação de Comunicação Social?

A partir do conteúdo encontrado no material pesquisado, foram construídos os capítulos da pesquisa em questão.

\section{O CRIME VIOLENTO LETAL INTENCIONAL}

A princípio é necessário que se possa compreender o que vem a ser 0 Crime Violento Letal Intencional e a motivação para que se estabeleça uma forma de reduzi-lo e eliminá-lo. Os Crimes Violentos Letais Intencionais (CVLI) compreendem todo crime violento que tenha como consequência a morte, sendo enquadrado nesse contexto como: homicídio doloso (quando uma pessoa mata outra intencionalmente), lesão corporal seguida de morte e latrocínio (roubo seguido de morte) (SILVA, 2015, p.62).

Esse tipo de crime é uma realidade vivida em todos os Estados do país e o número de ocorrências é estabelecido como um indicador de nível da violência. A preocupação com a o aumento desse delito pode ser exemplificada com os programas criados com o foco na redução desse índice de violência, a exemplo do Pacto pela Vida em Pernambuco, e com o número de atores envolvidos com a causa a fim de que os programas de redução da violência tenham resultados cada vez mais expressivos (PERNAMBUCO, 2014, p.16).

Pernambuco, ao longo de anos, vinha sofrendo com os números da violência e entre o ano 2000 e 2006, dentre todas as capitais das Unidades 
Federativas, Recife ostentou a triste imagem de capital com maior taxa de homicídios e em 2004 e 2005 Pernambuco apresentou a maior taxa de Crimes Violentos Letais Intencionais do Brasil com índices maiores que o dobro da média nacional. Esse dado serviu como alerta para algo que poderia ser mudado e indubitavelmente precisava ser combatido de forma enérgica e prioritária (PERNAMBUCO, 2014, p.16).

A relevância do tema CVLI para os Estados é muito grande. Devido a tal relevância o Instituto de Pesquisa Econômica Aplicada realizou em 2019 um Fórum Brasileiro de Segurança Pública que estabeleceu um Atlas da Violência contabilizando os números de homicídios por Estado e mostrando a realidade da violência no País. (IPEA, 2019, p.24)

A preocupação do Estado de Pernambuco em combater o CVLI cresce e é criado o Programa Pacto Pela Vida em 2007. A partir de então novas estratégias são traçadas para que haja o Fortalecimento do programa Pacto Pela Vida como a adoção do Modelo de Gestão Integrada do Poder Executivo do Estado de Pernambuco instituído através da Lei Complementar ㄲo 141, de 03 de setembro de 2009 (PERNAMBUCO, 2009).

Em 2012, visando a redução da criminalidade no Estado, foram criadas as Câmaras Técnicas do Pacto Pela Vida no âmbito do poder executivo Estadual através do Decreto oㅜ 38.576 de 27 de agosto de 2012. Essas Câmaras Técnicas estão divididas em 07, sendo elas: a Câmara de Defesa Social, a Câmara de Administração Prisional, a Câmara de Articulação do Poder Judiciário, Ministério Público e Defensoria, a Câmara de Prevenção Social, a Câmara de Políticas Sobre Drogas e a Câmara de Enfrentamento à Violência de Gênero Contra a Mulher (PERNAMBUCO, 2012).

Em 2013, o combate à violência é intensificado e as ações das câmaras Técnicas no Pacto Pela Vida passam a ter estratégias ainda mais definidas em busca de resultados. Essas ações começam a adotar o modelo de Gestão por Resultados estabelecido através do Decreto no 39.336, de 25 de abril de 2013 como instrumento de valor público que tem como um dos principais indicadores 
de resultados a taxa de Crimes Violentos Letais Intencionais (PERNAMBUCO, 2013).

A meta anual do Programa Pacto Pela Vida é estabelecida na redução de $12 \%$ do número de CVLI com base nos números do ano anterior. A busca constante de atingir essa meta tem a consequente melhora no posicionamento nacional com base na taxa de homicídios (PERNAMBUCO, 2014, p.17).

\subsection{Fatores que Podem Favorecer o Crime Violento Letal Intencional}

As causas de cometimento de crimes violentos letais intencionais são multifatoriais e muito difíceis de serem relacionadas objetivamente como uma fórmula para $o$ ato criminoso. A subjetividade que envolve o crime se dá quando leva-se em consideração tanto as características individuais do autor do crime, que pode ser entendida como os aspectos psicológicos e saúde mental do indivíduo, quanto as variáveis do contexto social em que o agressor está inserido, como densidade populacional, coeficiente de Gini (forma de monitorar a desigualdade de renda), pobreza, a taxa de analfabetismo, o Índice de Desenvolvimento Humano e desemprego, que podem estar associadas às taxas de violência criminal (SILVA, 2015, p.62).

$O$ fato de estarmos diante de algo bastante subjetivo pode ser exemplificado quando compreendemos que indivíduos que compartilham de uma mesma realidade social podem responder de maneiras bem diversas diante de variáveis iguais ou semelhantes às já mencionadas. Daí deve-se levar em consideração a percepção individual de cada um como suas experiências particulares de vida e como essas experiências foram tratadas ao longo do tempo. Essas experiências podem estar relacionadas com a educação familiar, hábitos, comportamentos, formação e valores adquiridos ao longo da vida, e podem exercer influência real na prática delituosa (SILVA, 2015, p.63).

Para Sento-Fé (2011, p.27) a esses fatores individuais podem ainda serem somados a alcoolemia, o uso de drogas, o aprendizado deficiente, a 
família desestruturada e históricos de vitimização infantil como variáveis que de fato estão ligadas diretamente ao crime como fatores de risco tanto na prevenção à evolução criminal, quanto no positivismo criminológico.

Nesse sentido, pode-se pontuar que o cometimento da ação delituosa de CVLI pode ser favorecido e então estar relacionado com uma sintonia ou soma de fatores de risco individuais e sociais e ainda com o estado mental e psicológico em que o indivíduo se encontra, momento em que a prática criminosa está mais disponível e pode se cruzar com a desorganização social e outros. Desse modo, os fatores de risco não devem ser pensados isoladamente, uma vez que, geralmente, eles se relacionam (ALVES; GONTIJO; ALVES, 2013, p.329).

\subsection{A Vulnerabilidade de Crianças, Adolescentes e Jovens}

Adultos que cometem crimes um dia foram crianças, adolescentes e jovens que ao longo de anos podem ter sido expostos a esses fatores de riscos individuais e sociais como: falta de recursos financeiros, privação de oportunidades, desigualdade social e marginalização e outros já mencionados no tópico anterior. Esse é o pensamento que deve despertar em todos a importância de se trabalhar com esse público antes de iniciar a vida adulta, reduzindo esses fatores de risco através de trabalhos, que dentre outros, podese frisar o trabalho social reforçando valores e construindo cidadania (SILVA, 2015, p.64).

Dados alarmantes da violência preocupam em todo o Brasil, sobretudo quando trazemos ao debate a temática do envolvimento do jovem, da criança e do adolescente. A morte prematura de jovens (15 a 29 anos) por homicídio é um fenômeno que tem crescido no Brasil (INSTITUTO DE PESQUISA ECONÔMICA APLICADA, 2019, p.25).

Somente no ano de 2017, o número de mortes por homicídio entre os jovens no Brasil foi de 35.783. Esse dado gera a maior taxa de homicídios dos últimos 10 anos, ficando em 69,9 homicídios para cada 100 mil jovens. 
Pernambuco aparece dentre os Estados com maior taxa de homicídios de jovens, ocupando a terceira colocação com a taxa de 133,0 atrás somente do Estado do Ceará com 140,2 e do Rio Grande do Norte com 152,3. Os números são mais desanimadores quando se verifica que no Brasil $51,8 \%$ dos óbitos de jovens entre 15 e 19 anos se deu por homicídios (INSTITUTO DE PESQUISA ECONÔMICA APLICADA, 2019, p.25).

Para Castro e Abramovay (2002, p.161) essas mortes precoces dos jovens são a tradução da vulnerabilidade à violência que é uma marca singular dos jovens, nestes tempos além de citar a falta de oportunidades de trabalho e de alternativas de lazer. Com dados tão expressivos e alarmantes como os apresentados, é de fato necessário que o Estado desenvolva um trabalho significativo voltado para os jovens. Para Sousa (1999, p.54) "a ausência de ação sobre as questões juvenis por parte do Estado pode converter-se numa fonte aguda de conflitos" e que pode abranger outros problemas nas relações interpessoais como o "prolongamento da dependência familiar (que pode intensificar os conflitos no convívio), dificuldades de inserção profissional e outros de natureza diversa como uso de drogas, delinquência, etc".

Crianças, Jovens e adolescentes têm suas vulnerabilidades uma vez que vivenciam fases da vida onde valores são construídos e precisam definir relacionamentos e condutas que adotarão em sua vida social. Essas relações e condutas estão sujeitas a influências externas, sejam elas da família, dos profissionais da escola ou dos colegas e amigos, e é nesse ponto onde existe um grande problema. Os estudos realizados por Alves, Gontijo e Alves (2013, p.329) relatam que em um trabalho realizado com jovens de comunidades carentes os próprios participantes consideram que as amizades podem determinar a entrada do jovem no mundo das drogas.

Ainda nesse mesmo trabalho com jovens de comunidades, Alves, Gontijo e Alves (2013, p.329) afirmam que os principais temas gerados espontaneamente durante as oficinas foram: droga, violência, relações com a polícia, sexualidade e relacionamentos interpessoais. Esses temas são 
oriundos do dia a dia dos jovens da comunidade que vivenciavam essas temáticas na prática, inclusive relatando o uso de drogas por estarem acessíveis e passarem boa parte do seu tempo inseridos nesse contexto dentro de suas comunidades. Os motivos para procurarem as drogas são diversos como vivência de violência doméstica, dificuldade financeira e para se sentiram pertencentes a um grupo. Esse último argumento mostra a carência desses indivíduos e o quanto é necessário mostrar aos jovens, crianças e adolescentes o quanto eles são importantes para a sociedade e seu papel enquanto membros atuantes dela.

Já falando especificamente dos jovens, a esses fatores individuais e sociais somam-se outros que agravam a situação: A falta de expectativas para o futuro e a falta de qualificação para o trabalho. Sousa (1999, p.62) afirma em seu trabalho que diante dos dados da violência e desemprego, órgãos públicos e governantes chegam à conclusão que o problema da marginalidade entre os jovens é decorrente principalmente da incapacidade que estes encontram para ingressar no mercado de trabalho e da falta de oportunidades anteriores.

A falta de experiência ou mesmo a falta de como provar a referida experiência, dentre outros motivos, dificulta a primeira inserção no mercado de trabalho devido a exigência de alguns empregadores. Os jovens, sobretudo os de comunidades menos favorecidas, demandam novos enfoques da educação e qualificação profissional, não acessíveis aos jovens de famílias pobres (CASTRO; ABRAMOVAY, 2002, p.149-150).

Castro e Abramovay (2002, p.151) realizaram entrevistas com jovens onde constataram que um desejo presente nos jovens de comunidades é o de se empregar logo. Para os jovens e seus pais há muita apreensão quanto às incertezas do futuro que não sabem se terão. $O$ trabalho então tem uma importância real e constantemente se coloca como referência de dignidade, futuro e forma de garantir a sobrevivência. É encarado como a possibilidade de constituir família, conquistar a independência financeira, aumentar a autoestima e merecerem respeito na sociedade (CASTRO; ABRAMOVAY, 2002, p.152). 
Alves, Gontijo e Alves (2013, p.329) constataram em seus trabalhos que os jovens, adolescentes e crianças devem ter o seu tempo preenchido com boas companhias e atividades e que pelo próprio relato dos envolvidos, isso poderia definir o uso de drogas ou não. Essa constatação ganha força nos relatos de Castro e Abramovay (2002, p.152) onde é enfatizada a importância, para os jovens, do trabalho como "forma de ocupação do tempo e da mente, o que os impediria de pensar em cometer qualquer infração". E semelhantemente aos relatos do trabalho supracitado, os jovens entrevistados por Castro e Abramovay também afirmam que, "se houvesse emprego, muitos jovens não estariam envolvidos em atividades ilícitas".

Em entrevista com uma diretora de projetos de uma ONG, Castro e Abramovay trazem um relato que ratifica esse pensamento quanto à importância da ocupação dos jovens:

Um problema é o desemprego e o outro é o pessoal não ter a questão da educação, um grande número não está estudando, uma parcela muito pequena que estuda. Desemprego gera o quê? Desmotivação, baixa autoestima; o fato de não estar estudando deixa eles despreparados para o mercado de trabalho e isso os leva a se envolver com outros tipos de atividades não saudáveis, como drogas e outras coisas.

\section{A COMUNICAÇÃO SOCIAL DO CORPO DE BOMBEIROS MILITAR DE PERNAMBUCO}

A Comunicação Social é uma atividade desenvolvida no CBMPE através do CCS - Centro de Comunicação Social. A unidade é dividida em 01 (uma) Chefia com cargo previsto de Tenente-Coronel; 01 (uma) Divisão de Ações Preventivas, cargo previsto de Major, 01 (uma) Seção de Imprensa e Jornalismo, cargo de Capitão, 01 (uma) Seção de Marketing e Relações Públicas, cargo de Capitão, 01 (uma) Seção de Cerimonial e Eventos, cargo de $2^{\circ}$ Tenente, cada uma com seu efetivo fixado em seu Quadro de Organização 


\section{Revista FLAMMAE}

Revista Científica do Corpo de Bombeiros Militar de Pernambuco

Artigo Publicado no Vol.07 N.18 - Edição Jan a Jun 2021 - ISSN 2359-4829

Versão on-line disponível em: http://www.revistaflammae.com

totalizando 48 (quarenta e oito) militares segundo o disposto no quadro a seguir (PERNAMBUCO, 2020, p.11).

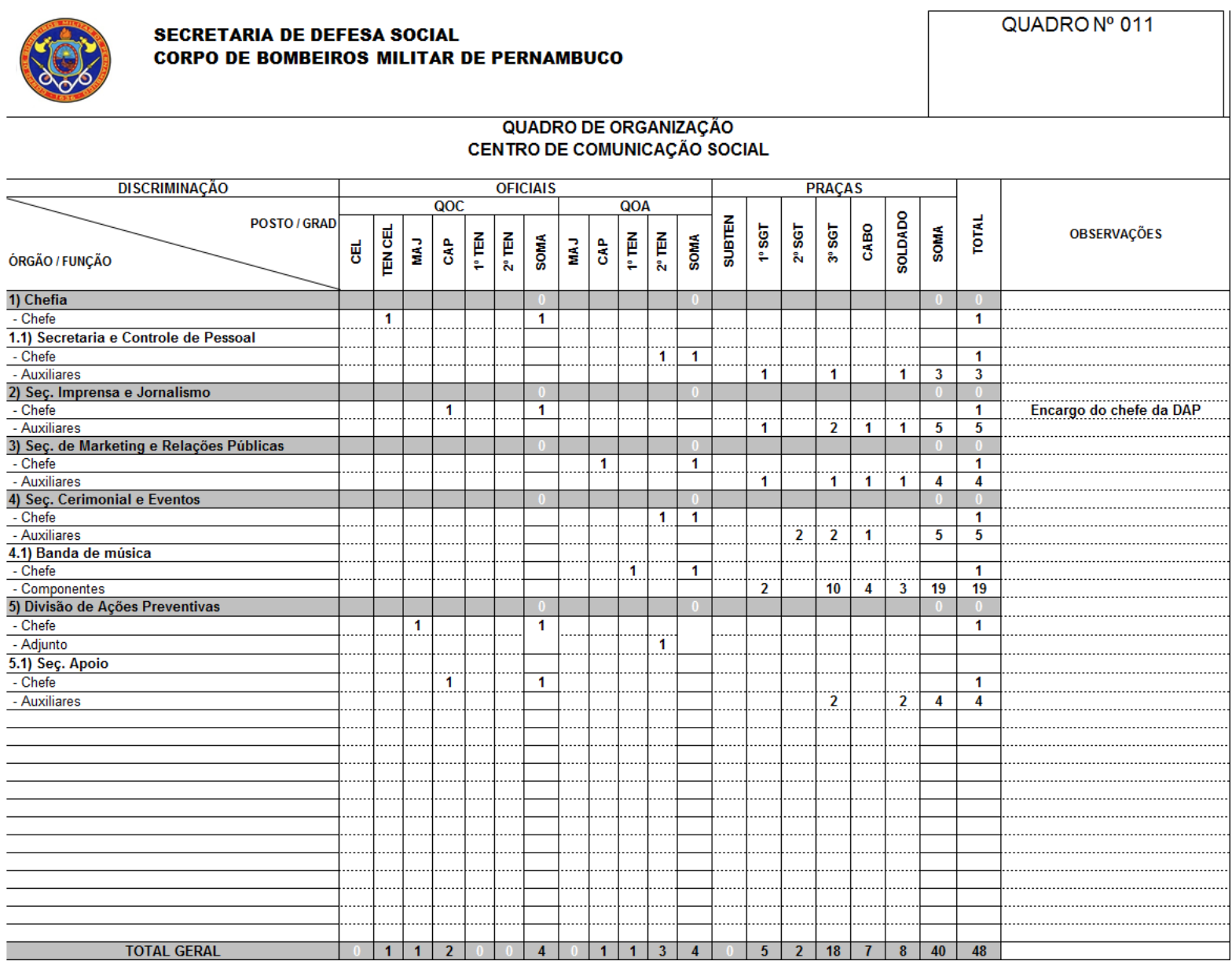

Fonte: Pernambuco, 2020, p.11.

O CCS tem como atividade ordinária a relação direta com os profissionais de imprensa com demandas relacionadas a toda a corporação, seja por orientações ao público levando medidas de prevenção, seja como fonte de informação acerca de ocorrências onde o CBMPE esteja atuando. Há ainda atividades ordinárias relativas ao desenvolvimento de imagens e campanhas de divulgação de conteúdos para redes sociais e mídias diversas com o fim de promover segurança e salvar vidas, bem como atualização de informações cadastrais de membros da corporação e de autoridades externas que tem como fim as relações públicas institucionais. Outras atividades do dia a dia do CCS estão relacionadas com o cerimonial militar, inerentes à rotina e 
aos eventos militares que acompanham toda a vida da instituição, tendo como marco recente a subordinação da banda de música do CBMPE ao centro. E por fim desenvolve ações sociais, educativas e preventivas voltadas para a população e instituições diversas (PERNAMBUCO, 2020, p.11).

\subsection{A Divisão de Ações Preventivas - DAP}

A Divisão de Ações Preventivas está subordinada diretamente ao Centro de Comunicação Social - CCS do CBMPE. O seu efetivo atual previsto no Quadro de Organização do CCS do CBMPE é de 07 (sete) militares sendo 01(um) Major, 01(um) Capitão, 01(um) 2०Tenente, 02(dois) $3^{\circ}$ Sargentos e 02(dois) Soldados. Sua ação está ligada à prevenção promovida por meio da informação que é levada a órgãos do Estado, escolas públicas e outras instituições públicas e privadas gerando educação preventiva para redução de acidentes e incidentes relacionados a incêndio, acidentes domésticos, afogamentos, alagamentos, manuseio de materiais inflamáveis, produtos químicos, eletricidade, queda e animais peçonhentos. Completando esses conteúdos, outras atividades são realizadas como palestras com a temática voltada às consequências e prejuízos causados por comunicação de falsas ocorrências (trotes) e promovidas oficinas de combate a incêndio, caso o órgão disponibilize local e material adequados para a prática, e atendimento préhospitalar com apresentação de um conteúdo básico para a prestação de um primeiro socorro a uma vítima qualquer. É importante enfatizar que esse trabalho educativo e de prevenção é uma das diversas formas de salvar vidas (PERNAMBUCO, 2020, p.11).

Além dessa atuação a DAP está inserida no Programa Governo Presente de Ações Integradas para Cidadania que é coordenado pela Secretaria de Políticas de Prevenção à violência e às Drogas e, segundo Clarissa $(2018$, p.1) trata-se de uma ação de cidadania refletida em mutirão que reúne serviços gratuitos de emissão de documentos, exames de saúde, 
orientações e atividades educativas. O Programa foi inserido na Política de Prevenção Social ao Crime e à Violência, como estratégia de prevenção social da violência e de intervenção estruturadora nos Territórios Especiais de Cidadania. A Lei no 14.357, de 14 de julho de 2011 no parágrafo único do seu artigo $1^{\circ}$ faz entender por "Territórios Especiais de Cidadania, a delimitação espacial de comunidades vulneráveis, identificados pela concentração de elevados índices de CVLI e situados nas AIS - Áreas Integradas de Segurança do Pacto Pela Vida" (PERNAMBUCO, 2011, p.1).

Diante do exposto, a ação de Comunicação Social do CBMPE começa aos poucos a se inserir através da DAP no enfrentamento ao CVLI, podendo ser ator de muita relevância para a redução de crimes em Pernambuco. Apesar do número de militares em seu efetivo ainda pequeno, conforme Pernambuco (2020, p.11), a DAP tem conseguido atender às demandas do CBMPE de forma a atingir o objetivo de salvar vidas através da informação. Tem conseguido também participar de forma positiva das ações do Programa Governo Presente, contribuindo para a Política de Prevenção Social ao Crime e à Violência. Essas ações têm um potencial de crescimento acentuado se atreladas a uma restruturação do quadro organizacional e incremento de recursos humanos e materiais à Divisão de Ações Preventivas, dando uma nova roupagem à atividade desenvolvida pela DAP e ampliando o conceito de Comunicação Social dentro da corporação.

\section{A AMPLIAÇÃO DAS AÇÕES DO CBMPE NOS PROGRAMAS GOVERNO PRESENTE DE AÇÕES INTEGRADAS PARA CIDADANIA E PACTO PELA VIDA ATRAVÉS DA COMUNICAÇÃO SOCIAL DA DAP - PROJETO DE INTERVENÇÃO}

A lei $n^{\circ} 16.569$ de 15 de maio de 2019 que institui a política de prevenção social ao crime e à violência em Pernambuco no seu capítulo III, Seção II, no art. $4^{\circ}$, dispõe sobre as diretrizes dessa política. Uma dessas 
diretrizes visa "desenvolver ações de reintegração econômica, política e social nos territórios contemplados pela Política de Prevenção Social ao Crime e à violência". Esses territórios contemplados são tratados como Territórios Especiais de Cidadania e são a delimitação espacial de comunidades vulneráveis com elevados índices de CVLI que estão situados nas AIS - Áreas de Integradas de Segurança do PPV - Pacto Pela Vida. Essa definição encontra-se na Lei no 14.357 de 14 de julho de 2011, em seu capítulo I como disposições gerais. É exatamente agindo em favor da reintegração econômica e social e almejando a redução do índice de CVLI que a DAP entra como promotora de ações de prevenção e capacitação direcionadas para crianças, adolescentes e jovens para, nesses territórios especiais, desempenhar o seu trabalho (PERNAMBUCO, 2011, p.1).

Em Relação a essa prevenção, segundo Sento-Sé (2011, p.21) existe tipos de prevenção a exemplo da primária que consiste numa "abordagem abrangente, que articula ações a partir da identificação de áreas e públicos potencialmente sujeitos a serem arrastados pela violência". As ações da DAP direcionadas para crianças e adolescentes se enquadram nesse tipo de prevenção buscando fortalecer valores sociais que são necessários para o exercício da cidadania. Ampliando a participação da DAP nos Programas Governo Presente de Ações Integradas para Cidadania e Pacto Pela Vida, com trabalhos em áreas vulneráveis pertencentes às AIS definidas no PPV, se fortalece os laços das crianças e adolescentes com a escola e com o Estado, que para Sento-Sé $(2011$, p.29) esses laços relativamente sólidos de pertencimento imbuídos de valores públicos razoavelmente cultivados tendem a reproduzir e consolidar virtudes públicas que mitigam o desvio e 0 comportamento criminal.

O fortalecimento desses laços vai naturalmente sendo estabelecido através das atividades que a DAP pode desenvolver utilizando de trabalhos de interação com o meio ambiente como passeios ao zoológico e ao jardim botânico atreladas ao conhecimento preventivo dos riscos de acidentes 
relacionados ao contato direto com os animais e plantas, e atividades que envolvem aventura como tirolesa, rapel guiado, falsa-baiana e passagem em pequenos túneis. Essas atividades oferecem às crianças e adolescentes experiências novas que geram a sensação de pertencimento e maior necessidade de envolvimento com o grupo de trabalho (SENTO-SÉ, 2011, p.29).

Pode-se ainda criar a Brigada Escolar nas escolas estaduais das AIS com ministrações semanais (44 semanas que compreendem o ano letivo) de palestras de prevenção de incêndio e atendimento pré-hospitalar, onde as crianças e adolescentes aprenderiam sobre os temas e teriam a elas atribuídas a responsabilidade de identificação de riscos no ambiente escolar, verificação semanal de equipamentos como extintores e kit de primeiros socorros e teriam simulações de abandono em caso de emergência com atribuições de líderes de evacuação. Essas atividades podem ter a configuração mês a mês da seguinte forma: Semana 1 - Acidentes domésticos; Semana 2 - Atendimento PréHospitalar; Semana 3 - Prevenção e Meio Ambiente; Semana 4 - Combate a incêndio; Semana 5 - Atividades Lúdicas. Nessas atividades da semana 5 acrescentam-se as atividades expressivas teatrais, os teatros de fantoches, apresentação de filmes e realização de os jogos coletivos e brincadeiras como o jogo da verdade, que para Alves, Gontijo e Alves (2013, p.329) possibilitam discussões no grupo sobre temas que muitas vezes é sugerido pelas próprias crianças e adolescentes que envolvem drogas e violência e que dá a possibilidade de trabalhar o tema num contexto social apregoando comportamentos aceitáveis num convívio em sociedade e desconstruindo comportamentos perigosos. Em concordância com essa afirmação, Carmo et al. (2010, p.55) diz que essas atividades em grupo com adolescentes "têm como objetivo abordar tema e/ou conteúdos necessários para a participação e compreensão da realidade social assim como possibilitar o acesso aos direitos". 
A ação da DAP ampliada e voltada para o público jovem se enquadra ainda na prevenção primária e estende-se à prevenção secundária como é definido por Sento-Sé (2011, p.22) como mais circunscrita. Ela diria respeito a populações e regiões identificadas como portadoras de características passíveis de serem identificadas como zonas de risco. Os jovens estão prestes a iniciarem suas vidas de trabalho e estão envolvidos emocionalmente com esse fato. Jovens entrevistados por Castro e Abramovay (2002, p.153) relataram algumas dificuldades comuns para conseguirem emprego e dentre elas estão a falta de experiência, a exigência do ensino médio, a falta de preparo escolar para a competição no mercado e a discriminação, seja racial, seja por residirem em comunidades periféricas.

Esse público então apresenta uma necessidade particular voltada para o trabalho e que precisa de alguma abordagem inicial. Nesse sentido a DAP, com a ampliação da sua atuação, poderá ministrar cursos de formação de Brigadistas de Emergência para jovens, em escolas estaduais presentes nas AIS, construindo conhecimentos teóricos e práticos nas áreas de atendimento Pré-Hospitalar, Abandono de Área e Combate a Incêndio que auxiliarão no currículo do jovem. Esses cursos têm carga horária mínima de 08 horas, podendo ser estendida para $20 \mathrm{~h}$, dentre atividades teóricas e práticas, estão previstos na NBR - 14276 e podem ser certificados pelos próprios membros da DAP. Os cursos devem ter validade de 12 meses e após esse período o brigadista precisará de atualização com $08 \mathrm{~h} / \mathrm{a}$ e nova certificação, segundo a Associação Brasileira de Normas Técnicas (2006, p.25). O Curso tem grande relevância por estar prevista a obrigatoriedade de que todas as empresas disponham de pessoas adestradas para o uso correto de equipamentos de proteção contra incêndio (NORMA REGULAMENTADORA - 23, 1996, p.1).

Essa ação, para Carvalho (2006, p.10) ganha efetividade quando integrada a um projeto retotalizador da política social como é o caso das qualificações e capacitações já realizadas pela Secretaria de Políticas de Prevenção à Violência e às Drogas, no Programa Juventude Presente, como 
os cursos profissionais de vendas, atendimento em turismo, informática, assistente administrativo, farmácia, barbearia, design de sobrancelhas, refrigeração, manutenção de motos, entre outros, conforme apresentam Lima e Muta (2019, p.1). Esses cursos são procurados pela população como alternativa de formação em curto prazo, possibilidade de construção de alternativas de trabalho e renda, segundo Silva, Massaro e Martinez (2017, p.3). A intenção é que ela seja um facilitador do ingresso do jovem no mercado de trabalho. Aliada a essa ação o CBMPE poderia atrelar descontos na Taxa de Prevenção e Extinção de Incêndio - TPEI e na Taxa de Vistoria - TV para a obtenção do Atestado de Vistoria do Corpo de Bombeiros - AVCB para o empregador que empregar jovens oriundos do programa e que passaram pelo curso de Brigadista de Emergência realizado pela DAP. Essa ação merece um estudo complementar futuro mais aprofundado a fim de identificar o impacto financeiro para o Estado.

Propostas como a capacitação profissional nas AIS e a estratégia da inserção produtiva da população empobrecida nas periferias das grandes cidades já estabelecida pela Secretaria de Políticas de Prevenção à Violência e às Drogas, tem se multiplicado como referência de intervenção da política social de assistência, bem como iniciativas das organizações sociais dos diversos segmentos (educação, saúde, assistência). O curso de Brigadista de Emergência a ser realizado pela DAP representa o entendimento desta proposta e se apresenta como oportunidade de início de novos ciclos, gestação de novos planos e projetos para os jovens das AIS (SILVA; MASSARO; MARTINEZ, 2017, p.3).

Com a atuação ampliada das ações da DAP tanto no Programa Governo Presente de Ações Integradas para Cidadania como no PPV será possível aumentar a empregabilidade de jovens em situação de riscos social e pessoal. Sua atuação possibilita o desenvolvimento pessoal e da estrutura familiar do jovem assistido, apresentando para a sociedade, indivíduos aptos ao mercado de trabalho, propiciando o desenvolvimento da comunidade local e oferecendo 
estabilidade financeira e dignidade à população envolvida (CAVALCANTE; BERNARDI; GARCIA, 2014, p.9).

\subsection{A Necessidade de Reestruturação da DAP para Atuação Ampliada nos Programas de Governo}

As ações já descritas representam uma projeção das ações que podem ser desenvolvidas pela DAP desde que haja uma reestruturação de seus recursos, tanto humanos como materiais. Essa reestruturação implica consequentemente na ampliação também do CCS - Centro de Comunicação Social do CBMPE a começar pelo seu QO - Quadro de Organização - QO (PERNAMBUCO, 2020, p.11).

Em conformidade com os dados contidos em Pernambuco (2019, p.9), toma-se como base para a modificação no QO do CCS o número de Áreas Integradas de Segurança - AIS, entendidas como a territorialização do Estado em 26 áreas de combate à criminalidade e diretamente ao CVLI, segundo Pernambuco (2014, p.18). Assim pode-se iniciar a intervenção nas cidades da Região Metropolitana do Recife - RMR a exemplo do Recife, Olinda, Paulista e Jaboatão dos Guararapes, que totalizam 08 AIS, áreas de atuação inicial da DAP para desenvolvimento das ações nos Programas Governo Presente de Ações Integradas para Cidadania e PPV. Essa definição de público alvo inicial apoia-se na verificação feita por Silva (2015, p.60) em que afirma haver um forte padrão de ocorrências de CVLI onde a densidade demográfica é maior, a exemplo da Região Metropolitana do Recife. Essa verificação repete-se quando se leva em consideração as 26 unidades federativas do Brasil (SILVA, 2015, p.63).

Ainda no ajuntamento de dados para a definição do QO do CCS, considera-se também o número de escolas estaduais de ensino integral da área descrita, levando-se em consideração também as EREM's - Escolas de Referência em Ensino Médio e as ETE's - Escolas Técnicas Estaduais, que servem como locais de atuação das equipes da DAP para a realização dos 
trabalhos. Esse número disponibilizado pela Secretaria de Educação e Esportes revela a existência de 104 escolas com regime de ensino integral ou semi-integral (PERNAMBUCO, 2020).

O Uso das escolas como locais de atuação da DAP leva em conta a constatação feita por França, Duenhas e Gonçalves (2013, p.712) que firmam que as escolas que se abriram para atividades complementares até mesmo quando utilizado o fim de semana apontaram melhoria nas relações entre os discentes, entre esses e os seus professores e ainda apresentaram redução do vandalismo na escola e o aumento do interesse da comunidade em relação à escola. Como resultado também houve o registro de redução de atentados contra a vida de alunos dentro da escola (FRANÇA; DUENHAS; GONÇALVES, 2013, p.725).

Sendo assim, para atendimento nas 08 AIS descritas em Pernambuco (2019, p.9) e 104 escolas de ensino integral ou semi-integral descritas em Pernambuco (2020), considerando que o trabalho a ser realizado pela DAP é de atividades semanais e que cada equipe de trabalho, definida com 04 componentes cada uma a fim de atender a NBR-14276, atende a 05 escolas, uma em cada dia da semana, totalizando 21 equipes de trabalho, a reestruturação em termos de recursos humanos para o CCS é necessária, passando a ser DCS - Diretoria de Comunicação Social tornando-se semelhante à estrutura que ocorre na $5^{\text {a }}$ Seção do EMG da Polícia Militar de Pernambuco, segundo seu Quadro de Organização, ressalvados os números de Praças que passa a ser superior. A DCS então deixa de ser Centro e assume o formato de Diretoria e seu efetivo, que antes era de 48 (quarenta e oito) militares, passa a ser de 134 (cento e trinta e quatro) militares levando-se em consideração o efetivo de Oficiais e Praças (PERNAMBUCO, 2020, p.30).

A DCS então deve passar a ter a seguinte configuração sugerida em relação à adequação dos Recursos Humanos, a fim de atender aos programas Governo Presente de Ações Integradas para Cidadania e Pacto Pela Vida: 
Revista Científica do Corpo de Bombeiros Militar de Pernambuco

Artigo Publicado no Vol.07 N.18 - Edição Jan a Jun 2021 - ISSN 2359-4829

Versão on-line disponível em: http://www.revistaflammae.com

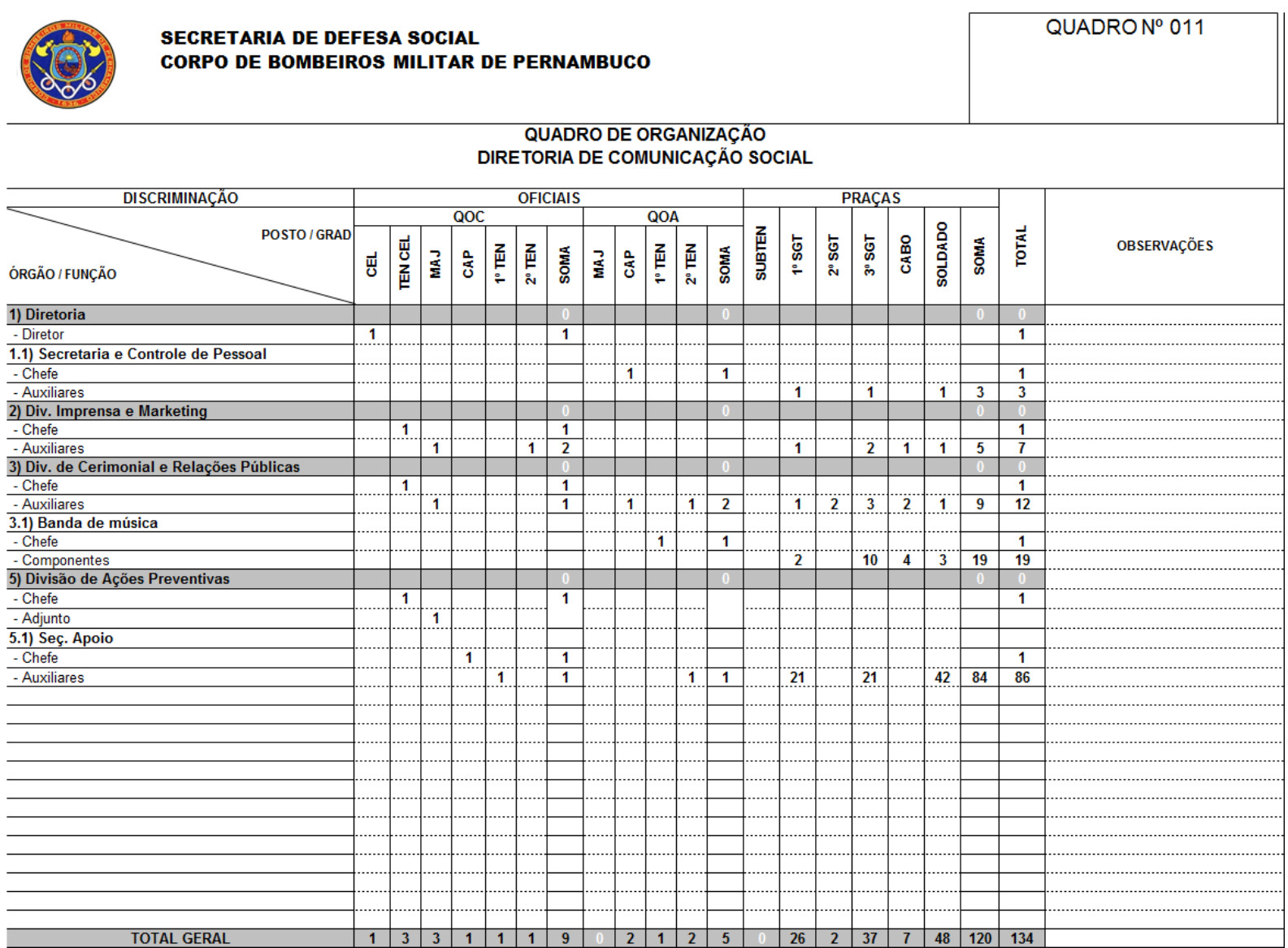

Fonte: Produção Própria

Outro incremento que deve ocorrer é o de Recursos Materiais que deve ser dimensionado para cada equipe de trabalho da DCS (21) com materiais de instrução teórica de Combate a Incêndio e instruções teórica e prática de Atendimento Pré-Hospitalar, além de uma viatura administrativa para cada equipe de trabalho. Leva-se em consideração também que a instrução prática para a formação dos brigadistas de emergência pode ocorrer na ABMG Academia Bombeiro Militar dos Guararapes com custeio de materiais necessários para a prática, e assim cumprir as exigências de conteúdo prático e teórico previstos na NBR - 14276 (ABNT NBR 14276:2006). 


\section{CONSIDERAÇÕES FINAIS}

Para Carvalho (2006, p.9) a governabilidade social passou a depender, cada vez mais, da participação dos diversos sujeitos do fazer social. Em Pernambuco, o Estado tem movimentado diversos atores para agir contra a violência e tem desenvolvido programas que têm o foco na política de prevenção à violência e às drogas e consequentemente reduzir a criminalidade e o cometimento de CVLI. Porém, devido a subjetividade da natureza da ação criminosa e toda a multifatorialidade envolvida é necessário que mais agentes se unam com o mesmo objetivo, desde órgãos públicos até a sociedade e mesmo o público alvo das ações desenvolvidas a fim de que se tenha efetividade.

Enquanto Estado, para $\mathrm{o}$ enfrentamento diário da violência e especificamente do $\mathrm{CVLI}$, com as adequações necessárias para o funcionamento da DAP, as ações sociais do Centro de Comunicação Social do Corpo de Bombeiros Militar de Pernambuco são promissoras quanto ao fortalecimento desse enfrentamento. Elas aproximam o Estado cada vez mais das pessoas, possibilitando o desenvolvimento pessoal e da estrutura familiar dos vulneráveis e apresentando alternativas de futuro àqueles que se encontram em áreas de risco e cujas vulnerabilidades se somam perigosamente (CAVALCANTE; BERNARDI; GARCIA, 2014, p.9).

Dessa forma, entendendo a Divisão de Ações Preventivas como agente promotor de segurança e de política contra a violência e as drogas, pode-se afirmar que sua ação contra a violência também é necessária na luta contra o crime. A ação da Comunicação Social do CBMPE contra a violência favorece o Estado a cumprir sua missão de inteligência do fazer público e, em consequência, a exercer seu papel indutor e articulador de esforços governamentais e societários em torno de prioridades da política pública (CARVALHO, 2006, p.9). 


\section{REFERÊNCIAS}

ALVES, I.; GONTIJO, D.T.; ALVES, H.C. Teatro do Oprimido e Terapia Ocupacional: uma proposta de intervenção com jovens em situação de vulnerabilidade social. cad. Ter. ocup. ufscar, Săo Carlos, v. 21, n. 2, p. 325-337, 2013. Disponivel em: hhttp://www.cadernosdeterapiaocupacional.ufscar.br/index.php/cadernos/article/ view/819/444> . Acesso em: 15 jan. 2020.

ASSOCIAÇÃO BRASILEIRA DE NORMAS TÉCNICAS. NBR 14276: Brigada de Incêndio - Requisitos. Rio de Janeiro. p.1-33, 2006.

BRASIL. Norma Regulamentadora 23. Segurança e Medicina do Trabalho. Proteção Contra Incêndios. São Paulo. 1996. Disponível em: $<$ https://www.normaslegais.com.br/legislacao/trabalhista/nr/nr23.htm >. Acesso em: 15 jan. 2020.

CARMO, A.S.; MENOTI, C.; DAVID, C.G.; OLIVEIRA, M.H. CRAS: um espaço de formação e capacitação dos jovens. Seminário Integrado. Faculdades Integradas Antônio Eufrásio de Toledo. Presidente Prudente, v. 4, p.49-58, 2010. Disponível em: <https://docplayer.com.br/25019460-Cras-um-espaco-deformacao-e-capacitacao-dos-jovens.html> . Acesso em: 15 jan. 2020.

CARVALHO, M.C.B. O Lugar da educação integral na política social. Cadernos Cenpec | Nova série, [S.I.], v. 1, n. 2, ago. 2006. ISSN 2237-9983. Disponível em:

$<$ http://cadernos.cenpec.org.br/cadernos/index.php/cadernos/article/view/166 > . Acesso em: 15 jan. 2020. doi:http://dx.doi.org/10.18676/cadernoscenpec.v1i2.166.

CASTRO, M.G.; ABRAMOVAY, M. Jovens em situação de pobreza, vulnerabilidades sociais e violências. Cad. Pesqui., São Paulo, n. 116, p. 143-176, Jul. 2002 Disponível em: $<$ http://www.scielo.br/scielo.php?script=sci_arttext\&pid=S0100-

$15742002000200007 \&$ Ing=en\&nrm=iso>. Acesso em: 15 jan. 2020. http://dx.doi.org/10.1590/S0100-15742002000200007.

CAVALCANTE, H.; BERNARDI, R.; GARCIA, D. Capacitação de Jovens do Ensino Médio das Escolas Públicas do Município de Tucuruí Através de Cursos na Área Metal-Mecânica. Revista Universo \& Extensão, América do Norte, 1, maio 2014.2 Disponível em: $<$ http://www.revistaeletronica.ufpa.br/index.php/universo extensao/article/view/ 409/151>. Acesso em: 15 jan. 2020. 
CLARISSA, C. Programa Governo Presente chega à marca de mais de 300 mil atendimentos em 2018. Sistema de Informação e Gestão da Assistência Social de Pernambuco, Recife, dez. 2018. Notícia. Disponível em: < https://www.sigas.pe.gov.br/noticia/programa-governo-presente-chega-amarca-de-mais-de-300-mil-atendimentos-em-2018> Acesso em: 13 abr. 2020.

FRANCA, M.T.A.; DUENHAS, R.A.; GONCALVES, F.O. Melhoria da qualidade educacional e redução da violência através de abertura de escolas públicas nos finais de semana: uma avaliação quantitativa. Ensaio: aval.pol.públ.Educ., Rio de Janeiro, v. 21, n. 81, p. 711-738, Dec. 2013 . Disponível em:

http://www.scielo.br/scielo.php?script=sci abstract\&pid=S0104-

40362013000400005\&lng=en\&nrm=iso\&tlng=pt >. Acesso em: 15 Jan. 2020.

GOLDENBERG, M. A arte de Pesquisar. Rio de Janeiro: Record, 1997.

IPEA - Instituto de Pesquisa Econômica Aplicada. Atlas da Violência 2019. Fórum Brasileiro de Segurança Pública. Brasília: Rio de Janeiro: São Paulo. 2019.

Disponível em: $<$ http://www.ipea.gov.br/portal/images/stories/PDFs/relatorio institucional/1906 05 atlas da violencia 2019.pdf> Acesso em: 03 Abr. 2020.

LIMA, J.; MUTA, J. Paulo Câmara Entrega 400 Certificados do Programa Juventude Presente. Blog da Folha. Recife, 24 out. 2019. Disponível em: < https://folhape.com.br/politica/politica/pernambuco/2019/10/24/BLG,12911,7,11 68,POLITICA,2419-PAULO-CAMARA-ENTREGA-400-CERTIFICADOSPROGRAMA-JUVENTUDE-PRESENTE.aspx >. Acesso em: 23 abr. 2020.

MINAYO, M. C. S. (Org.). Pesquisa social: teoria, método e criatividade. Petrópolis: Vozes, 2001.

PERNAMBUCO. Secretaria de Defesa Social. Organização Básica do Corpo de Bombeiros Militar de Pernambuco. Quadros de Organização e Distribuição. abr. 2020. Disponível em: https://www.intranet.bombeiros.pe.gov.br/page/publications/ome/7/tag/35>. Acesso em: 13 abr. 2020.

PERNAMBUCO. Secretaria de Defesa Social. Organização Básica da Polícia Militar de Pernambuco. Quadros de Organização e Distribuição. mar. 2020.

PERNAMBUCO. Secretaria de Defesa Social. Boletim Geral da Polícia Militar de Pernambuco $n^{\circ}$ A 1.0.00.0 248 de 30 de dezembro de 2019. $3^{\text {a }}$ Parte. Da Secretaria de Planejamento e Gestão. dez. 2019. Disponível em: < 
http://www2.pm.pe.gov.br/c/document library/get file?p | id=13026\&folderld=5 7930395\&name=DLFE-420201.pdf >. Acesso em: 15 abr.2020.

PERNAMBUCO. Secretaria de Educação e Esportes. Relação das Escolas com Seus Respectivos Diretores e Endereço 2020. mar. 2020. Disponível em:<http://www.educacao.pe.gov.br/portal/?pag=1\&men=77>. Acesso em: 15 abr.2020.

PERNAMBUCO. Secretaria de Planejamento e Gestão. Coleção Cadernos de Boas Práticas de Gestão. Volume V. Pacto Pela Vida. Recife, 2014.

PERNAMBUCO. Lei Complementar n ${ }^{\circ}$ 141, de 03 de setembro de 2009. Dispõe sobre o Modelo Integrado de Gestão do Poder Executivo do Estado de Pernambuco. Recife: Assembleia Legislativa do Estado de Pernambuco, [2009]. Disponível em:

https://legis.alepe.pe.gov.br/texto.aspx?tiponorma=2\&numero=141\&complemen to $=0 \& a n o=2009 \&$ tipo $=\& u r l=>$. Acesso em: 20 ago 2020.

PERNAMBUCO. Lei $\mathbf{n}^{\circ} \mathbf{1 4 . 3 5 7}$, de 14 de julho de 2011. Institui o Programa Governo Presente de Ações Integradas para Cidadania, e dá outras providências. Recife: Assembleia Legislativa do Estado de Pernambuco, [2011].

Disponível em:

http://legis.alepe.pe.gov.br/texto.aspx?id=1177\&tipo=TEXTOATUALIZADO >

Acesso em: 13 abr. 2020.

PERNAMBUCO. Lei $\mathrm{n}^{\circ} \mathbf{1 6 . 5 6 9}$, de 15 de maio de 2019. Institui a Política de Prevenção Social ao Crime e à Violência no Estado de Pernambuco. Recife: Assembleia Legislativa do Estado de Pernambuco, [2019]. Disponível em: $<$ http://legis. alepe.pe.gov.br/Paginas/texto.aspx?id=45781\&tipo=>. Acesso em: 13 abr. 2020.

PERNAMBUCO. Decreto $\mathrm{n}^{\circ}$ 38.576, de 27 de agosto de 2012. Cria as Câmaras Técnicas do Pacto Pela Vida e dá outras providências. Recife: Governo do Estado de Pernambuco, [2012]. Disponível em: < https://legis.alepe.pe.gov.br/texto.aspx?id=8363>. Acesso em: 20 ago. 2020.

PERNAMBUCO. Decreto $n^{\circ}$ 39.336, de 25 de abril de 2013. Estabelece 0 Valor Público como objetivo dos Programas do Estado, fixa diretrizes para a Gestão por Resultados, e estabelece a execução dos Pactos de Resultados no âmbito do Poder Executivo Estadual. Recife: Governo do Estado de Pernambuco, [2013]. Disponível em: < http://www.sad.pe.gov.br/c/document library/get file?uuid=1fa27e1e-b2c44bd0-9cc4-b89430d0562b\&groupld=11927>. Acesso em: 20 ago. 2020. 
SENTO-SE, T.J. Prevenção ao crime e teoria social. Lua Nova, São Paulo, n. 83, p. 9-40, 2011 Disponível em: < http://www.scielo.br/scielo.php?pid=S0102$64452011000200002 \&$ script=sci abstract\&ting=pt $>$. Acesso em: 15 Jan. 2020.

SILVA, E.P.; MASSARO, M.A.; MARTINEZ, M.B. O Significado dos Cursos de Capacitação Profissional para os Moradores da Comunidade de Paraisópolis uma aproximação com os indicadores de resultados. In: III Seminário Nacional de Território e Gestão de Políticas Sociais, 2017, Londrina-PR, Anais do II Congresso Internacional de Política Social e Serviço Social: Desafios $\begin{array}{llllll}\text { Contemporâneos, } & 04 & \text { a } & 07 & \text { de julho. } & 2017 .\end{array}$ Disponível em: <http://portalintercom.org.br/anais/nacional2015/resumos/R100154-1.pdf>. Acessado em: 15 jan. 2020.

SILVA, T.P. Análise Espacial e Avaliação de Vulnerabilidade Socioeconômica para os Crimes Violentos Letais Intencionais (CVLI) no Estado de Pernambuco. Geoingá: Revista do Programa de Pós-Graduação em Geografia. Maringá, v.7, n.2, p.60-77, 2015. Disponível em:< http://periodicos.uem.br/ojs/index.php/Geoinga/article/view/49312>. Acesso em: 15 jan. 2020.

SOUSA, J.T.P. Os Jovens, as Políticas Sociais e a Formação Educativa. Revista de Ciências Humanas. Florianópolis, Ed. UFSC, n.26, p.51-79, out. 1999. https://periodicos.ufsc.br/index.php/revistacfh/article/viewFile/23907/21413>. Acesso em: 15 jan. 2020. 